\title{
Studies on the Harm, Flight Ability and Host Selection of Sirex noctilio
}

\author{
Li Siteng ${ }^{1}$, Tao Jing ${ }^{2}$, * \\ ${ }^{1}$ Beijing 101 High School, Beijing, P. R. China \\ ${ }^{2}$ Key Laboratory for Silviculture and Conservation of Ministry of Education, Beijing Forestry University, Beijing, P. R. China \\ Email address: \\ 15801522619@163.com (Li Siteng), taojing1029@hotmail.com (Tao Jing) \\ ${ }^{*}$ Corresponding author
}

To cite this article:

Li Siteng, Tao Jing. Studies on the Harm, Flight Ability and Host Selection of Sirex noctilio. American Journal of Entomology. Vol. 3, No. 3, 2019, pp. 61-65. doi: 10.11648/j.aje.20190303.12

Received: July 15, 2019; Accepted: August 20, 2019; Published: September 10, 2019

\begin{abstract}
In order to determine the damaging characteristics of Sirex noctililo, we used five-point sampling mode to conduct a survey, investigating the number, characteristics, and vertical distribution of the emergence holes. We also studied the damaging characteristics of the larva in the forest farm where the pest naturally occurs. By conducting host preference research in a laboratory environment, we predicted the potential hosts of Sirex noctililo and observed the ovipositional behavior of female adults. The flight capacity of the adult Sirex noctililo of 1-7 days of age was tested for 24 hours in a Jiaduo flight mill system. Total flight distance, total flight duration, and average flight speed were recorded. According to the results, the emergence holes of Sirex noctililo were positively circular, and the diameter was about $2.10-7.00 \mathrm{~mm}$ and distributed in the trunk height of $0-4$. $20 \mathrm{~m}$, having distinct difference with that of the emergence holes of other species of borer pests. he larvae's tunnels displayed circular cross-sections and were filled with feces and xylem-colored bore dust. Additionally, unlike some borers, the S. noctilio larvae's tunnels lacked fras holes. Sirex noctililo had a distinct preference for Pinus tabuliformi Carr. and Pinus massoniana Lamb. The one-day-old adults had maximized flight capacity, relying on which Sirex noctililo could spread $18.71 \mathrm{~km}$ annually. The study provides a reliable reference point for identifying and monitoring Sirex noctililo in the field in China. Moreover, the study preliminarily assesses the risk of Sirex noctililo continuing to spread.
\end{abstract}

Keywords: Sirex noctilio, Invasive Species, Damaging Characteristics, Oviposition, Flight Capacity

\section{Introduction}

Sirex noctilio Fabricius, belonging to Hymenoptera, Siricidae, Sirex, is a significant international quarantine forest pest [1]. It has been identified as an invasive species with very high risk by North American Plant Protection Organization. $S$. noctilio is endemic to Europe and Northern Africa. In 1900, New Zealand became the first territory that $S$. noctilio invaded outside of its natural habitat. From then on, S. noctilio invaded Australia in 1952, Uruguay in 1980, Argentina in 1985, Brazil in 1988, South Africa in 1994, Chile in 2000, and United States in 2005. It has engendered tremendous economic loss in these countries [2-8].

In July 2013, S. noctilio, an international quarantine forest pest, was confirmed as an invasive pest of China. $S$. noctililo has appeared in Heilongjiang province, Jilin province, and the
Inner Mongolia Autonomous Region [9]. Once the pest spreads further, it will cause enormous loss in forest resources of China. Being a newly invasive forest pest, entomologists have not thoroughly studied $S$. noctilio in its morphology, biology, and ecology in China, posing difficulties to the prediction of the occurrence of $S$. noctilio in early stages. This study firstly investigated the morphology and damaging characteristics of $S$. noctilio, providing reliable reference to identify $S$. noctilio. Second, the host preference was investigated under a laboratory environment, and the ovipositional behavior was observed. Finally, the flight capacity of the adults of different days of age was studied to gain insight into the spreading ability of $S$. noctilio. Determining the characteristics mentioned above was significant to the prediction and prevention of S. noctilio. 


\section{Materials and Methods}

\subsection{Insect Materials}

Collect naturally emergent adults from Pinus sylvestris var. mongolica, 150 centimeters in length, from Junde Forest Farm, Hegang City, Heilongjiang Province, place in rearing cages, and record the date of emergence.

\subsection{Investigating Damaging Characteristics}

Cut down trees with $S$. noctilio occurrence and chop them into logs measuring 35 centimeters in length. Number the logs. Count and measure the number, diameter, and vertical distribution of the emergence holes. Chose logs only with $S$. noctilio occurrence, chopping them into 15 centimeter-long cross-sections in order to study the characteristics of larva's tunnels. Cut the 15 centimeter-long sections into 6-8 pieces vertically to number the tunnels corresponding to different emergence holes respectively. Record tunneling patterns in photographs. After cleaning the feces from the tunnels, trace the tunnels from the emergence holes to find the initial ovipositional sites. Pay attention and record the horizontal distance from the deepest points in the tunnels to the surface of the logs, the starting depth of the tunnels, and the horizontal and vertical distance between emergence holes and ovipositional sites.

\subsection{Host Collection}

Use ten pine species, including $P$. sylvestris var. mongolica, P. tabuliformis, P. armandii, P. massoniana, P. elliottii, $P$. kesiya var. langbianensis, P. koraiensis, Larixgmelinii, $P$. yunnanensis and $P$. taeda, to conduct the host preference study. In this study, the pine species were chosen according to the following principles: (i) widely distributed in China; (ii) economically or ecologically significant. Take ten 1-meter-long logs for each pine species, 100 logs in total, and place them in the net shed. The net shed was made of gauze and shade cloth, with dimensions 7 meters long, 7 meters wide, 2 meters tall. The logs were arranged in squares of 10 logs by 10 logs, with 60 centimeters between each of the logs. Each of ten species was contained in one column. To prevent the moisture loss and to keep the logs fresh, each cross-section produced by cutting is sealed with the mixture of melted wax and water.

\subsection{Host Preference and Observing Ovipositional Behavior}

The study was conducted during the emergence period of $S$. noctilio, from August 6th to 12th. Collect 40 females and 150 males newly emergent adults and put into the net shed every day, letting them mate freely. Observe the ovipositional behavior of female adults every day of the study during 9:00-12:00 and 13:00-17:00, and record the number of oviposition on each log. After the 7-day period, calculate the total oviposition time on each log to generate a chart to be used to determine the tendency of host preference. Ovipositional behavior was recorded using a Nikon D800 and $105 \mathrm{~mm}$ macro lens. Use marker to mark the ovipositional sites immediately after oviposition. In order to study the ovipositional characteristics, some $\operatorname{logs}$ were cut at ovipositional sites as marked. The logs' left integral was used to observe the growth of larvae one month after oviposition, and they were reared under an appropriate environment during the one-month period.

\subsection{Determination of the Flight Capacity}

Collect adults with similar size and place each one in a jelly cup with upper aperture of 7.5 centimeters, bottom diameter of 6 centimeters, and height of 3.9 centimeters. Rear the insects under appropriate environment (temperature of $25^{\circ} \mathrm{C}$ and moisture of $50 \% \sim 60 \%$ ). Male and female adults of different ages were selected for the flight test. The flying instrument used a 32-channel Jiaduo insect flying mill system built by Henan Jiaduo Company. The flying mill boom is a stainless-steel wire, 20 meters long and 0.2 millimeters in diameter. Before the test, a small amount of insect glue was taken from the end of the boom and quickly bonded to the front and back of $S$. noctilio. During the test, the flying mill boom was placed on the flying mill, and wood wasp was tangentially rotated around the central axis of the boom. The test was carried out under the conditions of temperature $25^{\circ} \mathrm{C}$, humidity $50 \% \sim 60 \%$, no wind, and light intensity $200 \sim 350$ lumens, and the test time was $24 \mathrm{~h}$. The adult life span of $S$. noctilio in China is generally 7 days. Therefore, the male and female $S$. noctilio adults are set to 7 groups according to their age, that is, from 1 to 7 days old. At least 6 were tested per treatment and tested once per $S$. noctilio. Record and analyze the cumulative flight distance, cumulative flight time, average flight speed, etc. of $S$. noctilio. Each flight parameter was calculated by the system's analysis software.

\subsection{Statistical Analysis}

GraphPad Prism 7.00 software was used for mapping, and one-way ANOVA was statistically significant using SPSS 22.0 software. Multiple comparisons were performed using Duncan's method.

\section{Results}

\subsection{Damaging Characteristics of S. noctilio}

The larvae of $S$. noctilio bored the trunk of host. The tunnels of the larvae are labyrinthine, seriously damaging the water and nutrient transportation system of the host, one of the main reasons for the death of the host. By anatomizing the trunk where oviposition occurred, the study showed that the starting depth of oviposition is from $0.3 \mathrm{~cm}-0.6 \mathrm{~cm}$, which is related to the length of the ovipositors of $S$. noctilio. The vertical distances between emergence holes ranged from 0 centimeters to 7 centimeters and the horizontal distances range from 0.8 centimeters to 10 centimeters. When the larvae bored the wood, they pushed back their feces and bore dust which compactly filled the tunnel. As the feces had the same color as the wood, it was difficult to identify some of the tunnels. Through analyzing the damaging characteristics of 
the tunnels, the larvae seldom bored the wood horizontally. Under most conditions, they bored upward or downward, and there was no distinct difference between number of larvae boring upward and downward. The tunnels occasionally show L-shape or U-shape characteristics, but they had no obvious shape under most conditions. About half of the larvae bored to the core or even through the core of the host.

According to the survey, three species of pest, including $S$. noctilio, Asemum amurense, and Phaenops sp., could simultaneously infest Pinus sylvestris var. mongolica, yet they had different damaging characteristics. S. noctilio has circular emergence hole with diameter of 2.10-7.00 milimeters. Phaenops sp. has D-shaped or half-moon-shaped emergence holes which are slightly smaller than that of $S$. noctilio. A. amurense, on the contrary, always infest the decayed part in the bottom of the host. The emergence holes of $A$. amurense are oval and are bigger than that of $S$. noctilio. The larvae and emergence holes of $A$. amurense distribute at a height of 0 meters to 1.05 meters from the trunk. Phaenops sp.'s emergence holes distribute in the range of 0 meters to 5 meters from the trunk, whereas the larvaew are all in the range of 2.10-2.80 meters from the trunk. This indicates that $A$. amurense mainly bores the bottom of the host, while $S$. noctilio and Phaenops sp. bores from the bottom to the top of the host's trunk.

\subsection{Host Preference Study Under Lab Circumstance}
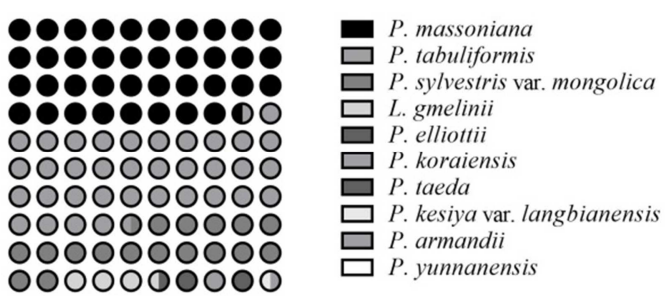

Figure 1. Proportion of eggs laid by Sirex noctilio females on different pine trees.

Under laboratory circumstances, the portion of total oviposition time on each species of pine is shown below. The time of oviposition on each of 10 species of pine have distinct differences. The pine species are listed according to the duration of oviposition time on each species of pine from longest to shortest: $P$. massoniana $>P$. tabuliformis $>P$. sylvestris var. mongolica $>$ Larixgmelinii $>P$. elliottii $>P$. koraiensis $>$ P. taeda $=P$. kesiya var. langbianensis $>P$. armandii $>$ P. yunnanensis. Among the pines, $P$. massoniana and $P$. tabuliformis were distinctly preferred by $S$. noctilio, the degree of oviposition on which were $38.34 \%$ and $36.70 \%$ respectively. $P$. sylvestris var. mongolica follows these two species, taking up $17.07 \%$ of the oviposition time occurred. Other 7 species were less preferred.

\subsection{Oviposition Process of Sirex noctilio}

The ovipositor of a female adult $S$. noctilio is a needle-like organ at the end of the abdomen, either beige or puce in color. The length of the ovipositor is approximately 8 millimeters, slightly shorter than that of the primaries. The ovipositor is covered by two sheathes. The oviposition apertures are circular holes with rough edges created by the pits of the ovipositor. There is one visible oviposition aperture on the outside of the phloem yet 1-4 on the interior surface, corresponding to 1-4 oviposition drillings in the xylem. The radiating oviposition drillings differ in depth, either carrying or not carrying eggs. The egg of $S$. noctilio is a whitish, translucent cambi form, 1.30-1.60 millimeters in length and approximately 0.30 milimeters in width. Thirty minutes after oviposition, resin flux occurs, an important determinant of the identification of the $S$. noctilio's occurrence. One month after oviposition, a blue stain appears in the xylem of the host, caused by the fungi, Amylostereum areolatum (ChailletexFr.Boidin) (Russulales: Amylostereacea) carried by female adults.

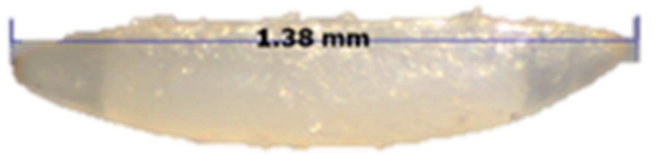

Figure 2. Egg of Sirex noctilio.

\subsection{Flight Capacity of Sirex noctilio}

The adults of $S$. noctilio do not consume any food, having a longevity of 7 days on average $[10,11]$. The flight speed, flight duration, and total distance were examined and recorded by the flight mill system which tested the flight capacity of adults of both genders between 1 to 7 days of age. The result is showed in Figure 3.
A

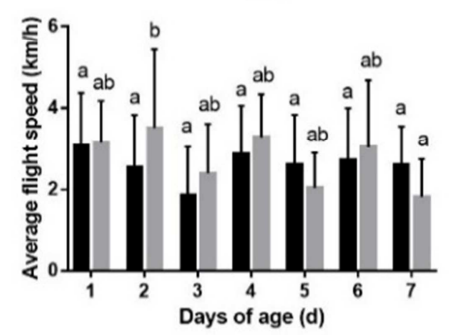

B

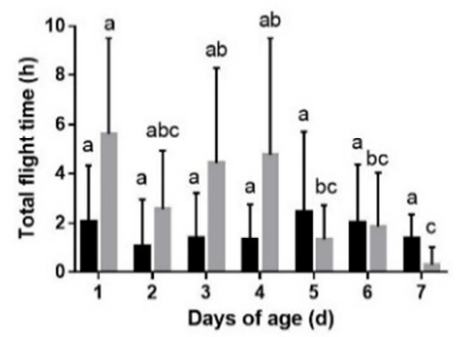

C

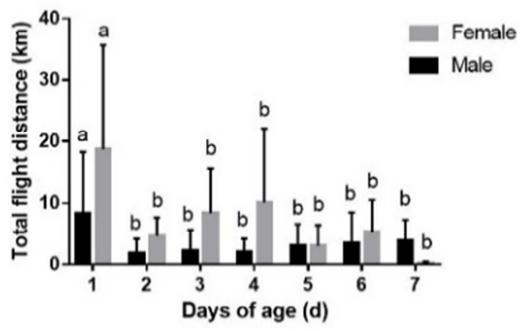

Different lowercase letters for females or males indicate significant differences (one-way ANOVA followed by Turkey's multiple comparison tests, $P<0.05$ ).

Figure 3. Flying ability of Sirex noctilio females and males. 
The flight speed did not differ between males of different ages, while the flight speed of the female adults of 2 days old distinctly surpassed that of adults of 7 days of age. The flight time did not vary significantly for male adults of 1-7 days of age either. The flight time of the females of 1 day old was longer than that of the females of 7 days old, yet the distinction was not obvious for that of the females of 2-6 days old. The flight time of the females of 1 day old surpassed that of the males of 1 day old by $174.63 \%$, and the differences for adults in other days old showed the same tendency. The adults of 1 day old, both male and female, exceeded adults of 2-7 days old in flight distance remarkably. The total distance covered by the female adults of 1 day old exceeded that of the males of 1 day old by $125.69 \%$ while the difference applied to that of adults at other ages.

\section{Discussion}

Summarizing the analysis of the damaging characteristics of $S$. noctilio, I concluded that the key to the identification of $S$. noctilio is "ERBT", where "E" refers to the circular emergence holes with diameter of 2.10-7.00 millimeters, "R" refers to the resin flux from the oviposition apertures after oviposition, "B" refers to the blue stain in xylem caused by the fungi $S$. noctilio carries, and "T" refers to the larva's labyrinthine tunnels filled with feces and bore dust.

The study shows that $S$. noctilio especially prefers $P$. massoniana, $P$. tabuliformis, and P. sylvestris var. mongolica as hosts, which can be found in all provinces in China except Xinjiang Uyghur Autonomous Region, Tibet Autonomous Region, Hong Kong Special Administrative Region, and Macau Special Administrative Region. This indicates that $S$. noctilio have the potential infest forests, nation-wide. Additionally, given its invasive history, $S$. noctilio adapts extremely well, enabling it to cause enormous damage even without the presence of preferred hosts. Given that, we should be cautious about the spread of $S$. noctilio at a national scale.

The study also determines that age remarkably influences the flight capacity of adults. The one-day-old female adults can cover the maximum distance, 18.71 kilometers. Even though $S$. noctilio seemed adept at disseminating its population because of flight capacity, the result demonstrates that it still is difficult for a single $S$. noctilio adult to widely proliferate by itself. Recent field studies suggest that $S$. noctilio dispersal within a forest is very limited, less than 150 meters [12, 13]. Given these constraints, the best strategy for $S$. noctilio seems to be to alight in a nearby tree and use its final resources for ovipositional activity [14]. The regions where $S$. noctilio occur are adjacent to the habitats of $P$. tabuliformis, meaning that proper prevention in advance is necessary.

The study, most significantly, summarizes the damaging characteristics of $S$. noctilio, presenting them in the form of a method for rapid identification in the field. The host preference study provides insight in to the proliferation of $S$. noctilio at the national scale, which is a significant reference for the prevention of the pest. Moreover, the study provides basic yet important data to determine the factors influencing the flight capacity of $S$. noctilio. Further research in host preference, flight capacity, and their influencing factors are needed to give reasonable, specific advice and instruction for the prediction, prevention in advance, and control of $S$. noctilio [15].

\section{Conclusion}

In northeast China, $S$. noctilio displays the same typical damaging characteristics as other countries. While in Heilongjiang, $S$. noctilio only chooses $P$. sylvestris var. mongolica in the field, under laboratory conditions, $S$. noctilio also chooses Pinus tabuliformi Carr. and Pinus massoniana Lamb., two other commonly occurring pines in China, as hosts. S. noctilio has rather strong flight capacity, meaning that it can, and very likely, also spread naturally without the the help of artificial media. The harm, host selection, ovipositional behavior, flight capacity of S. noctilio are the basis of further study on $S$. noctilio's risk assessment, monitoring, and control.

\section{References}

[1] Q. Xu, L. J. Cao, J. P. Ma, et al (2018). Study on the morphology and damage characteristics of Sirex noctilio. Journal of Environmental Entomology. 40 (02): 299-305.

[2] JL Madden (1988). Sirex in Australasia. Dynamics of forest insect populations: Springer. 407-429.

[3] M. P. Ayres, J. M. Sullivan, T. Harrison, et al (2009). Diagnosing the presence of Sirex noctilio from examination of dead and dying pine trees. Report for USDA APHIS.

[4] A. J. Carnegie, R. H. Eldridge, D. G. Waterson (2005). History and management of Sirex woodwasp in pine plantations in New South Wales, Australia. New Zealand Journal of Forestry Science. 35 (1): 3.

[5] A. G. Farji-Brener, J. C. Corley (1998). Successful invasions of hymenopteran insects into NW Patagonia. Ecología austral. 8 (02): 237-249.

[6] S. W. Myers, K. E. Zylstra, J. A. Francese, et al (2014). Phenology and flight periodicity of Sirex noctilio (Hymenoptera: Siricidae) in central New York, USA. Agricultural and forest entomology. 16 (2): 129-135.

[7] G. D. Tribe (1995). The woodwasp Sirex noctilio Fabricius (Hymenoptera: Siricidae), a pest of Pinus species, now established in South Africa. African Entomology. 3 (2): 215-217.

[8] E. T. Iede, S. R. C. Penteado and E. G. Schaitza (1998). Sirex noctilio problem in Brazil: detection, evaluation, and control. Pages45-52 In Proceeding of a Conference: Training in the Control of Sirex noctilio by the Use of Natural Enemies. USDA Forest Service, FHTET 98-13.

[9] X. B. Liu, Z. J. Zheng, F. Zhou, et al (2017). Effects of age (in days), gender and nematode infection on the flight capacity of Sirex noctilio. Chinese Journal of Applied Entomology. (6): 933-939. 
[10] D. M. Keeler (2012). Flight period and species composition of Sirex (Hymenoptera: Siricidae) and associated Deladenus (Nematoda: Neotylenchidae) within Arkansas pine forests. Dissertations \& Theses-Gradworks.

[11] K. Ryan, B. P. Hurley (2012). Life history and biology of Sirex noctilio, The Sirex Woodwasp and its Fungal Symbiont: Springer, Dordrech. 15-30.

[12] J. C. Corley, J. M. Villacide (2012). Population dynamics of Sirex noctilio: influence of diapause, spatial aggregation and flight potential on outbreaks and spread, The Sirex Woodwasp and its Fungal Symbiont: Springer, Dordrecht. 51-64.
[13] A. S. Martínez, J. Villacide, A. A. A. Fernández, et al (2014). Sirex noctilio flight behavior: toward improving current monitoring techniques. Entomologia Experimentalis et Applicata. 152 (2): 135-140.

[14] O. A. Bruzzone, J. M. Villacide, C. Bernstein, et al (2009). Flight variability in the wood wasp Sirex noctilio (Hymenoptera: Siricidae): an analysis of flight data using wavelets. Journal of Experimental Biology. 212 (5): 731-737.

[15] L. J. Haavik, J. D. Allison, C. J. K. MacQuarrie, et al (2016). Nonlethal effects of nematode infection on Sirex noctilio and Sirex nigricornis (Hymenoptera: Siricidae). Environmental entomology. 45 (2): 320-327. 